Department of

Chronic Diseases and

Environmental

Epidemiology,

National Institute of

Public Health and the

Environment,

3720 BA Bilthoven,

The Netherlands

C Tabak

H A Smit

A Menotti

E J M Feskens

Department of

Environmental

Sciences,

Environmental and

Occupational Health

Group, Wageningen

Agricultural University,

Wageningen,

The Netherlands

C Tabak

D Heederik

The Netherlands

Institute for Health

Sciences (NIHES),

Erasmus University,

Rotterdam,

The Netherlands

C Tabak

Division of Nutrition,

University of Helsinki,

Helsinki, Finland

L Räsänen

Nutrition Section,

Department of

Internal Medicine and

Endocrinological and

Metabolical Sciences,

University of Perugia,

Perugia, Italy

F Fidanza

Division of

Epidemiology, School

of Public Health,

University of

Minnesota,

Minneapolis,

Minnesota 55455, USA

A Menotti

Department of Public

Health and General

Practice, University of

Kuopio and

Department of

Neurology, Kuopio

University Hospital,

FIN-70211 Kuopio,

Finland

A Nissinen

Division of Public

Health Research,

National Institute of

Public Health and the

Environment,

Bilthoven,

The Netherlands

D Kromhout

Correspondence to:

Ms C Tabak

\title{
Dietary factors and pulmonary function: a cross sectional study in middle aged men from three European countries
}

\author{
Cora Tabak, Henriette A Smit, Leena Räsänen, Flaminio Fidanza, Alessandro Menotti, \\ Aulikki Nissinen, Edith J M Feskens, Dick Heederik, Daan Kromhout
}

\begin{abstract}
Background-Results of epidemiological studies relating individual dietary factors to chronic obstructive pulmonary disease (COPD) are inconsistent. To evaluate the cross sectional association of dietary factors with pulmonary function, data were collected from middle aged men in three European countries.

Methods-The data were collected in the 1960 s in Finland $(n=1248)$, Italy $(n=$ 1386), and the Netherlands $(n=691)$. Dietary intake was estimated using the cross-check dietary history method. Forced expiratory volume $\left(\mathrm{FEV}_{0.75}\right.$ or $\mathrm{FEV}_{1}$, here called FEV) was measured by spirometry. Associations were adjusted for age, height, smoking, body mass index (BMI), alcohol consumption, and energy intake.
\end{abstract}

Results-FEV was positively associated with intake of vitamin $E$ in Finland, with intake of fruit in Italy, and with intake of $\beta$-carotene in the Netherlands. In all three countries men with intakes of both fruit and vegetables above the median had a higher FEV than those with a low intake of both foods. The difference in FEV ranged from 110 to $169 \mathrm{ml}$ before and from 53 to $118 \mathrm{ml}$ after energy adjustment. Differences in FEV for intake of three antioxidants (vitamins $C$ and $E$ and $\beta$-carotene) above versus below the median ranged from 61 to $181 \mathrm{ml}$ before and from -35 to $58 \mathrm{ml}$ after energy adjustment. Intake of fish was not associated with FEV.

Conclusions-In three European countries a high intake of fruit and vegetables was positively associated with pulmonary function. A high intake of all three antioxidants tended to be positively associated with pulmonary function before, but not after, adjustment for energy intake. Associations of individual antioxidants with pulmonary function were not consistent across countries.

(Thorax 1999;54:1021-1026)

Keywords: diet; pulmonary function; fruit; vegetables; antioxidants

Several epidemiological studies have investigated the relation between diet and chronic obstructive pulmonary disease (COPD). A possible protective effect against the development of respiratory symptoms, diagnosed
COPD, or a decline in pulmonary function has been observed for dietary antioxidants ${ }^{1-9}$ and/or fruit, ${ }^{10-13}$ and for N-3 fatty acids and/or fish intake. ${ }^{14-16}$ Antioxidants and foods rich in antioxidants such as fruit are thought to protect the airways against oxidant mediated damage ${ }^{17}$ while the N-3 fatty acids mainly present in fish are thought to have anti-inflammatory effects through their influence on the metabolism of arachidonic acid. ${ }^{18}$

The results of studies investigating the relation between antioxidant factors and COPD related outcomes are not consistent, and vary according to the different outcomes studied, whether intake or plasma levels of antioxidants were studied, and whether only dietary intake of antioxidants or intake of supplements was also included.

Observed associations between intake of antioxidants from diet only and pulmonary function are reasonably consistent with regard to vitamin $\mathrm{C}$ and fruit intake. ${ }^{1-368-13}$ The two studies that did not find a statistically significant association of pulmonary function with intake of vitamin $\mathrm{C}$ and fruit or fruit and vegetables were characterised by a small number of subjects $(\mathrm{n}=178)^{3}$ or cases (=obstruction, $\mathrm{n}=95) .{ }^{8}$ Inconsistent results have been obtained on the effect of dietary intake of vitamin $E$ or $\beta$-carotene on pulmonary function. Dow et $a l^{\beta}$ observed a positive association between vitamin $\mathrm{E}$ intake and pulmonary function, but no association was observed in two other studies. ${ }^{2}{ }^{6}$ Intake of $\beta$-carotene was positively associated with forced expiratory volume in one second $\left(\mathrm{FEV}_{1}\right)$ and forced vital capacity (FVC) in the study by Grievink et al but not in that by Chuwers et al. ${ }^{5}$

The magnitude of the effect of individual dietary factors on pulmonary function observed so far is small. ${ }^{19} \mathrm{~A}$ small amount of misclassification of dietary intake may therefore have a substantial effect on the studied associations. Furthermore, one dietary factor with antioxidant capacity may not be a good indicator of the antioxidant status in the lungs related to diet. It may therefore be better to study the joint effect of several antioxidant factors on pulmonary function.

In the 1960 s data on pulmonary function and diet were collected in Finland, Italy, and the Netherlands according to the Seven Countries Study protocol. ${ }^{20}$ We have studied pulmonary function in relation to dietary intake of antioxidant (pro-)vitamins, fruit, vegetables, and fish. Furthermore, we have tried to estab- 
Table 1 Baseline data and at re-examination after five and 10 years of follow up in the Finnish, Italian, and Dutch participants of the Seven Countries Study

\begin{tabular}{llll}
\hline & Finland & Italy & Netherlands \\
\hline Examination 1 (baseline) & & & \\
$\quad$ Year of examination & 1959 & 1960 & 1960 \\
Age range (years) & $40-59$ & $40-59$ & $40-59$ \\
No. of men examined & 1677 & 1712 & 872 \\
Response rate & $98 \%$ & $99 \%$ & $80 \%$ \\
Data on diet (n) & - & - & - \\
Data on pulmonary function (n) & 1614 & 1646 & - \\
Examination 2 (5 year follow up) & & & \\
Year of examination & 1964 & 1965 & 1965 \\
Age range (years) & $45-64$ & $45-64$ & $45-64$ \\
No. of men examined & 1531 & 1548 & 778 \\
Response rate (\% of survivors) & $97 \%$ & $95 \%$ & $93 \%$ \\
Data on diet (n) & - & 1539 & 721 \\
Data on pulmonary function (n) & 1491 & 1394 & 694 \\
Used in present analysis (n) & & 1386 & 691 \\
Examination 3 (10 year follow up) & & & \\
Year of examination & 1969 & 1970 & 1970 \\
Age range (years) & $50-69$ & $50-69$ & $50-69$ \\
No. of men examined & 1363 & 1335 & 701 \\
Response rate (\% of survivors) & $95 \%$ & $88 \%$ & $91 \%$ \\
Data on diet (n) & 1306 & $592 \star$ & 615 \\
Data on pulmonary function (n) & 1325 & 1069 & - \\
Used in present analysis (n) & 1248 & & \\
\hline
\end{tabular}

$-=$ data not available.

$\star$ Only measured in Crevalcore. interviews were carried out by extensively trained dieticians and nutritionists. Although the dietary history method was adapted to the local situation in each specific country, the methodology was comparable. The nutrient intake was assessed using computerised versions of the local food tables for the three different countries. ${ }^{22-24}$

Pulmonary function was measured by spirometric tests. Equipment and protocols differed between the countries but were identical in each country. In Finland forced expiratory volume in 0.75 seconds $\left(\mathrm{FEV}_{0.75}\right)$ was measured with a McKerrow spirometer. Subjects were measured in a sitting position and with use of a noseclip. The $\mathrm{FEV}_{0.75}$ was established in three attempts. In Italy $\mathrm{FEV}_{0.75}$ was measured with a Pulmonor Jones spirometer with the subjects standing and wearing a noseclip. The highest value for $\mathrm{FEV}_{0.75}$, produced in two or three attempts, was used in the analyses. In the Netherlands forced expiratory volume in one second $\left(\mathrm{FEV}_{1}\right)$ was measured with a Godart Pulmotest by one technician. ${ }^{25}$ Subjects were measured sitting in an upright position. The mean of the two highest values of $\mathrm{FEV}_{1}$ established in three attempts was used. Assuming that the relation with diet is the same for $\mathrm{FEV}_{0.75}$ and $\mathrm{FEV}_{1}$, the term FEV without further specification will be used.

Information on age, height, weight, smoking, and work related physical activity was collected in a standardised way. ${ }^{20}$ Body mass index (BMI) was calculated (weight $/$ height $^{2}$ ) and work related activity level was defined as $1=$ bedridden, 2 = sedentary, $3=$ moderately active, and $4=$ hard physical work. Pack years of smoking were calculated as the product of the number of years smoked and the number of packs of cigarettes smoked per day. Former and current smokers indicated the number of cigarettes smoked: $1-4,5-9,10-19,20-29, \geqslant 30$ cigarettes/day and the mid points of these categories $(2,7,15,25,35)$ were used in the calculations. Former smokers were also asked to indicate how many years ago they stopped smoking. It was assumed that in all cohorts the men started smoking at the age of 16 , as known for the Zutphen cohort. A pack of cigarettes was assumed to contain 25 cigarettes. mercial town in the east of the Netherlands.

Complete data on diet, pulmonary function, and potential confounders were available for 1248, 1386, and 691 men in Finland, Italy and the Netherlands, respectively; data on pulmonary function were missing for 29, 149, and 28 subjects, respectively. Some men were excluded from spirometric testing because they suffered from severe conditions including COPD, as judged by the examining physician. The men with missing lung function data had a lower energy intake than those with a complete record in all three countries and energy adjusted intake of fruit and/or vitamin C tended to be lower.

\section{EXAMINATIONS}

Food intake was estimated using the crosscheck dietary history method, providing information about the usual food consumption pattern $6-12$ months preceding the interview. ${ }^{21}$ All

\section{STATISTICAL ANALYSIS}

The cross sectional relation between FEV and dietary factors was analysed using multiple linear regression analysis. Several models for the dependence of FEV on height and age were evaluated. Considered were models with FEV, its logarithm, or FEV divided by height squared $\left(\mathrm{FEV} / \mathrm{ht}^{2}\right)$ as the dependent variable and different forms and combinations of height and/or age as the independent variables. Selection of the "best" model was based on model simplicity, on the percentage of explained variance, and on inspection of residuals. The most parsimonious model with $\mathrm{FEV} / \mathrm{ht}^{2}$ as the dependent and age as the independent variable was chosen. In Finland and Italy all associations were adjusted for cohort. For ease of interpretation age adjusted results are pre- 
Table 2 Characteristics of the study population examined in 1969 in the Finnish and in 1965 in the Italian and Dutch cohorts of the Seven Countries Study

\begin{tabular}{|c|c|c|c|c|c|c|}
\hline & \multicolumn{2}{|c|}{ Finland $(n=1248)$} & \multicolumn{2}{|c|}{ Italy $(n=1386)$} & \multicolumn{2}{|c|}{ Netherlands $(n=691)$} \\
\hline & Mean & $S D$ & Mean & $S D$ & Mean & $S D$ \\
\hline Age (years) & 59.0 & 5.5 & 54.5 & 5.0 & 54.8 & 5.5 \\
\hline Height $(\mathrm{m})$ & 1.70 & 0.06 & 1.66 & 0.06 & 1.74 & 0.07 \\
\hline Smoking (pack years) & 21.4 & 17.0 & 15.1 & 15.0 & 19.5 & 13.9 \\
\hline $\mathrm{BMI}\left(\mathrm{kg} / \mathrm{m}^{2}\right)$ & 24.7 & 3.8 & 25.8 & 3.8 & 24.8 & 2.7 \\
\hline Alcohol (g) & 6.5 & 13.0 & 86.8 & 58.3 & 6.8 & 12.5 \\
\hline Total energy intake (MJ) & 15.6 & 4.7 & 12.5 & 3.1 & 12.4 & 2.7 \\
\hline Energy excl. alcohol (MJ) & 15.4 & 4.6 & 10.0 & 2.6 & 12.2 & 2.8 \\
\hline $\mathrm{FEV}^{\star}(\mathrm{ml})$ & 2703 & 733 & 2742 & 719 & 2960 & 699 \\
\hline Vitamin C (mg) & 91.7 & 35.3 & 45.9 & 24.0 & 91.8 & 39.5 \\
\hline Vitamin E (mg) & 6.7 & 2.4 & $9.9 \dagger$ & 3.6 & 17.9 & 6.6 \\
\hline$\beta$-carotene (mg) & 2.0 & 1.9 & $0.8 \dagger$ & 0.6 & 1.1 & 0.4 \\
\hline Fruit $(\mathrm{g})$ & 174 & 183 & 191 & 180 & 152 & 109 \\
\hline Vegetables (g) & 79 & 60 & 53 & 50 & 176 & 69 \\
\hline Fish $(\mathrm{g})$ & 39 & 46 & 21 & 20 & 17 & 23 \\
\hline
\end{tabular}

$\mathrm{BMI}=$ body mass index; FEV $=$ forced expiratory volume.

*In Finland and Italy $\mathrm{FEV}_{0.75}$ was measured and in the Netherlands FEV $t_{\mathrm{n}}=1356$.

\section{Results}

Intake of the different dietary factors showed a broad range across countries. Intake of vegetables, for instance, was highest in the Netherlands (mean $176 \mathrm{~g}$ ) and lowest in Italy (mean $53 \mathrm{~g}$ ). The Finnish men were on average five years older than the Italian and Dutch men (table 2).

Smoking was inversely associated with FEV in all countries $(\beta=-5$ to $-6 \mathrm{ml} /$ pack year, $\mathrm{p}<0.001)$. Energy intake was positively associated with FEV after adjustment for smoking, alcohol consumption, BMI, and work related activity level in Finland $(\beta=14 \mathrm{ml} / \mathrm{MJ}$, $\mathrm{p}<0.001)$ and in Italy $(\beta=34 \mathrm{ml} / \mathrm{MJ}, \mathrm{p}<0.001)$ but not in the Netherlands $(\beta=5 \mathrm{ml} / \mathrm{MJ}, \mathrm{p}=$ $0.54)$. Energy intake showed a positive association with vitamin $\mathrm{E}$ intake in all three countries and with vitamin $\mathrm{C}$ intake in Finland and Italy $(r=0.34-0.73, \mathrm{p}<0.001)$.

In table 3 the results of the regression analyses relating individual dietary factors to FEV are given. FEV was positively associated with intake of vitamins $\mathrm{E}$ and $\mathrm{C}(\mathrm{p}=0.05)$ in Finland, vitamins $\mathrm{C}$ and $\mathrm{E}$ and fruit in Italy, and with $\beta$-carotene intake in the Netherlands, after adjustment for smoking, alcohol consumption, and BMI. After subsequent adjustments for energy intake the FEV remained positively associated with intake of vitamin $\mathrm{E}$ in Finland, fruit in Italy, and $\beta$-carotene in the Netherlands.

From the data in tables 2 and 3 the increase in FEV per standard deviation (SD) increase in intake can be calculated. After adjustment for smoking, alcohol consumption, and BMI (model b) for vitamin $\mathrm{C}$ the FEV increased by $37 \mathrm{ml}$ per SD (95\% CI -0.3 to 74 ) in Finland and by $53 \mathrm{ml}(95 \% \mathrm{CI} 19$ to 87 ) per SD in Italy. For vitamin $\mathrm{E}$, the FEV increased by $93 \mathrm{ml}(95 \%$ CI 56 to 129) per SD in Finland and by $52 \mathrm{ml}(95 \%$ CI 15 to 89$)$ per SD in Italy. The increase in FEV with fruit intake was $68 \mathrm{ml}(95 \%$ CI 28 to 107$)$ per SD in Italy, $59 \mathrm{ml}(95 \% \mathrm{CI}-22$ to 140$)$ per SD in Finland, and $21 \mathrm{ml}(95 \% \mathrm{CI}-23$ to 65$)$ per SD in the Netherlands. formed using the SAS statistical package (Windows version 6.11, Cary, USA).

Table 3 Cross sectional association between $F E V^{*}(\mathrm{ml})$ and intake of antioxidants ( $\left.\mathrm{ml} / \mathrm{mg}\right)$, fruit or vegetables ( $\mathrm{ml} / \mathrm{g}$ ) in middle aged men in Finland $(n=1248)$, Italy $(n=1386)$, and the Netherlands $(n=691)$

\begin{tabular}{|c|c|c|c|c|c|}
\hline & \multicolumn{3}{|l|}{ Antioxidants } & \multicolumn{2}{|l|}{ Foods } \\
\hline & $\begin{array}{l}\text { Vitamin C } \\
\beta(95 \% C I)\end{array}$ & $\begin{array}{l}\text { Vitamin } E \\
\beta(95 \% C I)\end{array}$ & $\begin{array}{l}\beta \text {-carotene } \\
\beta(95 \% \text { CI) }\end{array}$ & $\begin{array}{l}\text { Fruit } \\
\beta(95 \% \text { CI })\end{array}$ & $\begin{array}{l}\text { Vegetables } \\
\beta(95 \% \text { CI })\end{array}$ \\
\hline \multicolumn{6}{|l|}{ Finland } \\
\hline Model a & $1.32(0.28$ to 2.36$)$ & $40.1(25.0$ to 55.3$)$ & $1.3(-18.1$ to 20.8$)$ & 0.23 (0.03 to 0.43$)$ & $0.13(-0.48$ to 0.74$)$ \\
\hline Model b & $1.04(-0.01$ to 2.09$)$ & $38.6(23.6$ to 53.7$)$ & $-2.9(-22.3$ to 16.4$)$ & $0.32(-0.12$ to 0.76$)$ & $-0.02(-0.63$ to 0.59$)$ \\
\hline Model c & $-0.51(-1.73$ to 0.71$)$ & $22.1(0.5$ to 43.8$)$ & $-15.8(-35.5$ to 3.9$)$ & $0.04(-0.41$ to 0.49$)$ & $-0.47(-1.10$ to 0.15$)$ \\
\hline \multicolumn{6}{|l|}{ Italy } \\
\hline Model a & $2.38(0.96$ to 3.80$)$ & $14.4(4.0$ to 24.8$)$ & $25.7(-30.7$ to 82.1$)$ & $0.40(0.19$ to 0.62$)$ & $0.52(-0.19$ to 1.24$)$ \\
\hline Model b & $2.19(0.77$ to 3.61$)$ & $14.6(4.2$ to 25.0$)$ & $29.3(-27.1$ to 85.8$)$ & $0.38(0.16$ to 0.59$)$ & $0.49(-0.23$ to 1.20$)$ \\
\hline Model c & $1.03(-0.47$ to 2.52$)$ & $-2.9(-15.4$ to 9.6$)$ & $1.1(-55.6$ to 57.9$)$ & $0.27(0.05$ to 0.49$)$ & $0.17(-0.54$ to 0.89$)$ \\
\hline \multicolumn{6}{|c|}{ The Netherlands } \\
\hline Model a & $0.94(-0.18$ to 2.06$)$ & $-3.2(-9.9$ to 3.5$)$ & 155.3 (40.9 to 269.8$)$ & $0.32(-0.08$ to 0.73$)$ & $0.52(-0.12$ to 1.16$)$ \\
\hline Model b & $0.69(-0.42$ to 1.79$)$ & $-2.8(-9.4$ to 3.9$)$ & 144.3 ( 31.3 to 257.3 ) & $0.19(-0.21$ to 0.59$)$ & $0.50(-0.13$ to 1.13$)$ \\
\hline Model c & $0.67(-0.44$ to 1.78$)$ & $-6.5(-14.6$ to 1.7$)$ & $141.1(27.4$ to 254.7$)$ & $0.19(-0.21$ to 0.59$)$ & $0.49(-0.14$ to 1.12$)$ \\
\hline
\end{tabular}

Model a: adjusted for height and age.

Model b: adjusted for height, age, smoking, body mass index (BMI), and alcohol consumption.

Model c: adjusted for height, age, smoking, BMI, alcohol consumption, and energy intake.

${ }^{\star}$ In Finland and Italy $\mathrm{FEV}_{0.75}$ was measured and in the Netherlands FEV $_{1}$. 
Table 4 Cross sectional association between FEV $(\mathrm{ml})$ and the combined intake of antioxidants, fruit, and vegetables in middle aged men in Finland, Italy, and The Netherlands

Difference in FEV (ml) between men with intake above versus below the median intake

\begin{tabular}{|c|c|c|c|c|c|c|}
\hline $\begin{array}{l}\text { Vitamin } C \\
\beta(95 \% C I)\end{array}$ & $\begin{array}{l}\text { Vitamin } E \\
\beta(95 \% \text { CI) }\end{array}$ & $\begin{array}{l}\beta \text {-carotene } \\
\beta(95 \% C I)\end{array}$ & $\begin{array}{l}\text { All three antioxidants* } \\
\beta(95 \% \text { CI })\end{array}$ & $\begin{array}{l}\text { Fruit } \\
\beta(95 \% C I)\end{array}$ & $\begin{array}{l}\text { Vegetables } \\
\beta(95 \% \text { CI })\end{array}$ & $\begin{array}{l}\text { Both foodst } \\
\beta(95 \% \text { CI })\end{array}$ \\
\hline $87 \mathrm{mg}$ & $6.4 \mathrm{mg}$ & $1.37 \mathrm{mg}$ & & $117 \mathrm{~g}$ & $65 \mathrm{~g}$ & \\
\hline $624 / 624$ & $624 / 624$ & $624 / 624$ & $284 / 280$ & $624 / 624$ & $622 / 626$ & $375 / 377$ \\
\hline 96 (23 to 169$)$ & 132 (58 to 205$)$ & $59(-14$ to 132$)$ & 206 (96 to 315$)$ & $117(44$ to 190$)$ & $48(-25$ to 121$)$ & $130(38$ to 220$)$ \\
\hline 83 (10 to 157$)$ & 125 (53 to 198$)$ & $40(-33$ to 112$)$ & 181 (71 to 291$)$ & 113 (33 to 193$)$ & $27(-46$ to 100$)$ & $110(11$ to 210$)$ \\
\hline $5(-76$ to 85$)$ & $23(-67$ to 112$)$ & $6(-67$ to 79$)$ & $48(-110$ to 197$)$ & $77(-4$ to 158$)$ & $-10(-83$ to 64$)$ & $53(-50$ to 156$)$ \\
\hline $42 \mathrm{mg}$ & $9.4 \mathrm{mg}$ & $0.65 \mathrm{mg}$ & & $150 \mathrm{~g}$ & $42 \mathrm{~g}$ & \\
\hline $692 / 694$ & $678 / 678$ & $678 / 678$ & $380 / 362$ & $657 / 729$ & $691 / 695$ & $278 / 316$ \\
\hline $63(-7$ to 133$)$ & $34(-40$ to 108$)$ & $45(-26$ to 117$)$ & $63(-48$ to 174$)$ & 125 (44 to 206$)$ & $84(11$ to 157$)$ & $194(83$ to 305$)$ \\
\hline $58(-11$ to 128$)$ & $34(-40$ to 108$)$ & $52(-20$ to 123$)$ & $61(-51$ to 173$)$ & 121 (40 to 202$)$ & $70(-3$ to 143$)$ & $169(56$ to 281$)$ \\
\hline $10(-61$ to 81$)$ & $-62(-143$ to 18$)$ & $24(-47$ to 96$)$ & $-35(-158$ to 871$)$ & $95(14$ to 176$)$ & $48(-24$ to 121$)$ & 118 (4 to 232$)$ \\
\hline $87 \mathrm{mg}$ & $17.6 \mathrm{mg}$ & $1.07 \mathrm{mg}$ & & $131 \mathrm{~g}$ & $165 \mathrm{~g}$ & \\
\hline $344 / 347$ & $345 / 346$ & $345 / 346$ & $110 / 116$ & $344 / 347$ & $340 / 351$ & $189 / 196$ \\
\hline $9(-80$ to 97$)$ & $-67(-155$ to 22$)$ & 138 (50 to 227 ) & 95 ( -59 to 249$)$ & $45(-43$ to 134$)$ & 97 (9 to 185$)$ & 131 (18 to 244$)$ \\
\hline $9(-79$ to 96$)$ & $-60(-147$ to 28$)$ & $138(51$ to 225$)$ & $108(-42$ to 257$)$ & $28(-59$ to 116$)$ & $84(-3$ to 172$)$ & $111(-3$ to 224$)$ \\
\hline $7(-81$ to 94$)$ & $-92(-189$ to 5$)$ & 136 (49 to 224$)$ & $58(-116$ to 233$)$ & $29(-59$ to 117$)$ & $83(-4$ to 170$)$ & $110(-4$ to 224$)$ \\
\hline
\end{tabular}

*Comparing men with intake of all three antioxidants above the median with those in whom the intake of all three antioxidants was below the median.

†Comparing men with intake of both fruit and vegetables above the median with those in whom the intake of both foods was below the median.

Model a: adjusted for height and age.

Model b: adjusted for height, age, smoking, body mass index (BMI), and alcohol consumption.

Model c: adjusted for height, age, smoking, BMI, alcohol consumption, and energy intake.

In all three countries FEV was higher in men with fruit and vegetable intakes above the median compared with those in whom the intake of both foods was below the median, after adjustment for smoking, BMI, and alcohol intake (table 4). Subsequent adjustment for energy intake reduced the observed difference in FEV in Finland (from $110 \mathrm{ml}$ to $53 \mathrm{ml}$ ) and Italy (from $169 \mathrm{ml}$ to $118 \mathrm{ml}$ ) but not in the Netherlands (from $111 \mathrm{ml}$ to $110 \mathrm{ml}$ ). FEV tended to be higher before but not after adjustment for energy intake in subjects with vitamin $\mathrm{C}$, vitamin $\mathrm{E}$, and $\beta$-carotene intakes above the median compared with those in whom the intake of all three antioxidants was below the median level (table 4).

Fish intake showed no clear association with FEV. After adjustment for all potential confounders the association was inverse and of borderline significance in Finland $(\beta=$ $-0.87 \mathrm{ml} / \mathrm{g}$ (95\% CI -1.73 to 0.00$)$ ) while in the Netherlands no association was observed $(\beta=-0.90 \mathrm{ml} / \mathrm{g}(95 \% \mathrm{CI}-2.78$ to 0.97$))$. In Italy the association was positive and of borderline significance before $(\beta=1.52 \mathrm{ml} / \mathrm{g}$ $(95 \% \mathrm{CI}-0.17$ to 3.22$)$ ) but not after $(\beta=$ $0.61 \mathrm{ml} / \mathrm{g}(95 \% \mathrm{CI}-1.11$ to 2.33$)$ ) adjustment for energy intake.

Intake of potatoes and margarine or oils, foods containing vitamins $\mathrm{C}$ or $\mathrm{E}$, were not associated with FEV. Bread consumption, however, was positively associated with FEV after adjustment for all potential confounders in Finland $(\beta=0.35 \mathrm{ml} / \mathrm{g}, \mathrm{SE}=0.17)$, Italy $(\beta$ $=0.41 \mathrm{ml} / \mathrm{g}, \mathrm{SE}=0.17)$, and the Netherlands $(\beta=0.57 \mathrm{ml} / \mathrm{g}, \mathrm{SE}=0.32)$. Mean $(\mathrm{SD})$ bread consumption was 253 (134) g, 348 (150) g, and 220 (89) g per day in Finland, Italy and the Netherlands, respectively.

When only men aged 50-64 years (the age range included in all three countries) were used in the analyses the observed associations remained essentially unchanged in Finland. In Italy and the Netherlands the observed associa- tions between individual dietary factors and FEV were generally somewhat stronger in the older subgroup. As a result the comparison of intake above and below the median levels for both fruit and vegetables was significantly associated with FEV in the Netherlands $(\beta=$ $151 \mathrm{ml}, \mathrm{SE}=69$ ).

\section{Discussion}

In middle aged men from three European countries the observed difference in FEV between men with high and low intakes of both fruit and vegetables (joint effect) ranged from 110 to $169 \mathrm{ml}$ before and from 53 to $118 \mathrm{ml}$ after adjustment for energy intake. Likewise, a change in FEV from $61 \mathrm{ml}$ to $181 \mathrm{ml}$ was observed before, and from $-35 \mathrm{ml}$ to $58 \mathrm{ml}$ after, adjustment for energy intake in men with a high intake of vitamin $\mathrm{C}$, vitamin $\mathrm{E}$, and $\beta$-carotene compared with those with a low antioxidant intake. Observed associations between individual dietary factors and pulmonary function were not consistent across the countries. After adjustment for all potential confounders, FEV was positively associated with intake of vitamin $\mathrm{E}$ in Finland, intake of fruit in Italy, and intake of $\beta$-carotene in the Netherlands.

The joint effect of fruit and vegetables, as defined here, may be less susceptible to misclassification of dietary intake and may reflect the effect of a more relevant difference in exposure, resulting in a more consistent and stronger association with pulmonary function across the countries. The groups that were compared to evaluate the joint effect were not extreme in their fruit or vegetable intake. The larger joint effect is therefore not caused by a larger difference in the fruit consumption between the compared groups alone.

Our results with the combined intake of vita$\min C$, vitamin $E$, and $\beta$-carotene are less clear. In the three countries antioxidant intake tended to be positively associated with FEV 
before but not after adjustment for energy intake. Energy intake was strongly and positively associated with pulmonary function in Finland and Italy with a substantial effect on all observed associations. Energy intake is, however, not a known risk factor for COPD. It is strongly associated with physical activity, but physical activity, even training, does not affect lung volumes. ${ }^{27}$ Energy intake may stand for another unknown factor associated with diet and pulmonary function, but in this case the factor may be an intermediate factor and not a confounder. It is therefore unclear whether energy adjusted or unadjusted results are more valid.

In contrast to other studies, ${ }^{14-16}$ but in accordance with a study on the relation between fish consumption and the 25 year incidence of chronic lung disease in the Dutch cohort, ${ }^{11}$ we observed no clear association between fish intake and pulmonary function.

Surprisingly, intake of bread was positively associated with FEV in all three countries with an increase in FEV from 47 to $62 \mathrm{ml}$ per SD increase in intake. An association between whole grain consumption and chronic diseases has been described by Slavin et $a l,{ }^{28}$ one of the proposed biological mechanisms of action being through the antioxidant capacity of several components of whole grains, including vitamin $\mathrm{E}$. It would be interesting to study the relation between the intake of whole grain products and COPD. Unfortunately, in our study information on the intake of the different types of bread-for example, white versus wholemeal-was not available.

A number of methodological aspects need to be addressed. Firstly, this study was cross sectional in nature and therefore a temporal relation between diet and pulmonary function cannot be established. Due to the relatively small number of subjects in the different countries, especially in the Netherlands, the power of our study may not be sufficient to detect small effects. Furthermore, although we adjusted for pack years of cigarette smoking, residual confounding by smoking cannot be excluded. Unfortunately it was not possible to repeat the analyses separately in the never smokers due to small numbers. Also, confounding by other health related lifestyle factors cannot be excluded, although work related physical activity, which can be seen as an indicator of socioeconomic status, could not explain the observed associations (results not shown).

The equipment used in the 1960s for measuring pulmonary function was less sophisticated than modern equipment. However, several studies performed in the 1960 s meet the current ATS reproducibility criteria. ${ }^{29}{ }^{30} \mathrm{As}$ a result of the differences in equipment and procedures used in the different countries and because in the Netherlands the $\mathrm{FEV}_{1}$ was measured rather than the $\mathrm{FEV}_{0.75}$, the level of FEV cannot be compared between countries. Comparisons within the three separate countries are, however, valid.

Vitamin C intake relative to the amount of fruit and vegetables ingested was low in Italy compared with Finland and the Netherlands. In the Netherlands potatoes (not included in vegetable intake) are the main source of vitamin $\mathrm{C}$, while in Finland the high vitamin $\mathrm{C}$ levels can be explained by the consumption of unpeeled potatoes and forest berries rich in vitamin $\mathrm{C}$. The relative amount of vitamin $\mathrm{C}$ derived from fruit is therefore likely to be highest in Italy. Other constituents of fruits such as flavonoids may also have a beneficial effect on pulmonary function. Whether this explains the stonger association between vitamin $\mathrm{C}$ and pulmonary function observed in Italy is, however, speculative. Unfortunately, data on the flavonoid intake of the study subjects in 1965-70 were not available.

In the different countries $4-10 \%$ of the men were excluded from the analyses due to missing pulmonary function data. Selection bias towards men with better pulmonary function may have occurred since men with a severe illness, including severe COPD, were excluded from spirometric testing. Furthermore, failure to perform an adequate pulmonary function measurement can be an indicator of impaired respiratory health. ${ }^{31}$ Since energy adjusted fruit and/or vitamin $\mathrm{C}$ intake tended to be lower in men with missing pulmonary function data, this selection may have caused these associations to be attenuated.

In conclusion, intake of both fruit and vegetables above the median level was positively associated with pulmonary function in three European countries. Intake of the three studied antioxidants (vitamin $\mathrm{C}$, vitamin $\mathrm{E}$, and $\beta$-carotene) above the median level tended to be positively associated with pulmonary function before but not after adjustment for energy intake. The associations of the individual dietary factors with pulmonary function were not consistent across countries. We postulate that the larger and more consistent joint effect of fruit and vegetable intake on pulmonary function might be the result of a more relevant and more stable difference in exposure.

1 Schwartz J, Weiss ST. Relationship between dietary vitamin $\mathrm{C}$ intake and pulmonary function in the First National Health and Nutrition Examination Survey (NHANES I) Am f Clin Nutr 1994;59:110-4.

2 Britton JR, Pavord ID, Richards KA, et al. Dietary antioxidant vitamin intake and lung function in the genera population. Am 7 Respir Crit Care Med 1995;151:1383-7.

3 Dow L, Tracey M, Villar A, et al. Does dietary intake of vitamins $\mathrm{C}$ and $\mathrm{E}$ influence lung function in older people? $A m$ $\mathcal{F}$ Respir Crit Care Med 1996;154:1401-4.

4 Ness AR, Khaw KT, Bingham S, et al. Vitamin C status and respiratory function. Eur F Clin Nutr 1996;50:573-9.

5 Chuwers P, Barnhart S, Blanc P, et al. The protective effect of $\beta$-carotene and retinol on ventilatory function in an asbestos-exposed cohort. Am ₹ Respir Crit Care Med 1997; 155:1066-71.

6 Grievink L, Smit HA, Ocké MC, et al. Dietary intake of antioxidant (pro)-vitamins, respiratory symptoms and pulmonary function: the MORGEN study. Thorax 1998;78 166-71.

7 Rautalahti M, Virtamo J, Haukka J, et al. The effect of alpha-tocopherol and beta-carotene supplementation on COPD symptoms. Am f Respir Crit Care Med 1997;156: $1447-52$

8 Morabia A, Sorenson A, Kumanyika SK, et al. Vitamin A, cigarette smoking, and airway obstruction. Am Rev Respir Dis 1989;140:1312-6.

$9 \mathrm{Hu} \mathrm{G}$, Zhang X, Chen J, et al. Dietary vitamin C intake and lung function in rural China. Am $f$ Epidemiol 1998; 148:594-9.

10 Strachan DP, Cox BD, Erzinclioglu SW, et al. Ventilatory function and winter fresh fruit consumption in a random sample of British adults. Thorax 1991;46:624-9. 
11 Miedema I, Feskens EJM, Heederik D, et al. Dietary determinants of long-term incidence of chronic nonspecific lun disease: the Zutphen study. Am $\mathcal{F}$ Epidemiol 1993;138:3745.

12 Cook DG, Carey IM, Whincup PH, et al. Effect of fresh fruit consumption on lung function and wheeze in children. Thorax 1997;52:628-33.

13 Carey IM, Strachan DP, Cook DG. Effect of changes in fresh fruit consumption on ventilatory function in healthy British adults. Am $\mathcal{F}$ Respir Crit Care Med 1998;158:728-33.

14 Schwartz J, Weiss ST. The relationship of dietary fish intak to level of pulmonary function in the first National Health
and Nutrition Survey (NHANES I). Eur Respir $\mathcal{f}$ and Nutrition

15 Sharp DS, Rodriquez BL, Shahar E, et al. Fish consumption may limit the damage of smoking on the lung. Am $\mathcal{F}$ Respir Crit Care Med 1994;150:983-7.

16 Shahar E, Folsom AR, Melnick SL, et al. Dietary n-3 polyunsaturated fatty acids and smoking-related chronic obstructive pulmonary disease. N Engl f Med 1994;331 228-33.

17 Sridhar MK. Nutrition and lung health: should people at risk of chronic obstructive lung disease eat more fruit and vegetables? BMF 1995;310:75-6.

18 Simopoulos AP. Omega-3 fatty acids in health and disease and in growth and development. Am F Clin Nutr 1991;54: 438-63.

19 Burney P. The origins of obstructive airways disease; a role for diet? Am 7 Respir Crit Care Med 1995;151:1992-3.

20 Keys A, Aravanis C, Blackburn H. Epidemiological studies related to coronary heart disease: characteristics of men aged 40-59 in seven countries. Acta Med Scand 1967; ppl): $1-392$.

21 Burke BS. The dietary history as a tool in research. $\mathcal{F} \mathrm{Am}$ Diet Assoc 1947;23:1041-6.
22 Den Hartog C, Schaik ThFSMv, Dalderup LM, et al. The diet of volunteers participating in a long term epidemiological field survey on coronary heart disease at Zutphen, The Netherlands. Voeding 1965;26:184-208.

23 Pekkarinen M. Dietary surveys in connection with coronary heart disease studies in Finland. In: Bazan NG, Paoletti R, Iacono JM, eds. New trends in nutrition, lipid research, and cardiovascular diseases. Current Topics in Nutrition and Disease, Vol 5. New York: Alan R Liss, 1981: 243-61.

24 Alberti-Fidanza A, Seccareccia F, Torsello S, et al. Diet of two rural population groups of middle-aged men in Italy. Int $\mathcal{F}$ Vitamin Nutr Res 1988;58:442-51.

25 Timmers J. Cardiorespiratory findings in a male working population. Thesis, Wolters-Noordhof, Groningen, 1969 (in Dutch, English summary).

26 Rothman KJ. Modern epidemiology. Boston: Little, Brown and Company, 1986.

27 McArdle WD, Katch I, Katch VL. Exercise physiology: energy, nutrition, and human performance. 3rd ed. Philadelphia/ London: Lea and Febiger, 1991.

28 Slavin J, Jacobs D, Marquart L. Whole grain consumption and chronic disease: protective mechanisms. Nutr Cancer 1997;27:14-21.

29 Becklake MR, Permutt S. Evaluation of tests of lung function for "screening" for early detection of chronic obstructive lung disease. In: Macklem PT, Permutt S, eds. The lung in the transition between health and disease. Vol 12. New York: Marcel Dekker; 1979: 345-87.

30 American Thoracic Society. Standardisation of spirometry 1987- update. Am Rev Respir Dis 1987;136:1285-98.

31 Ng'ang'a LW, Ernst P, Jaakola MS, et al. Spirometric lung function: distribution and determinants of test failure in a young adult population. Am Rev Respir Dis 1992;145:4852. 